\title{
Machine Learning-Based Classification and Regression Approach for Sustainable Disaster Management: The Case Study of APR1400 in Korea
}

\author{
Ahmed Abd El-Hameed (D) and Juyoul Kim *(D) \\ Department of NPP Engineering, KEPCO International Nuclear Graduate School, 658-91 Haemaji-ro, \\ Seosaeng-myeon, Ulju-gun, Ulsan 45014, Korea; eng.aelhameed@gmail.com \\ * Correspondence: jykim@kings.ac.kr; Tel.: +82-52-712-7306
}

Citation: El-Hameed, A.A.; Kim, J.

Machine Learning-Based

Classification and Regression

Approach for Sustainable Disaster Management: The Case Study of APR1400 in Korea. Sustainability 2021, 13, 9712. https://doi.org/10.3390/ su13179712

Academic Editor: Barry D. Solomon

Received: 2 August 2021

Accepted: 27 August 2021

Published: 30 August 2021

Publisher's Note: MDPI stays neutral with regard to jurisdictional claims in published maps and institutional affiliations.

Copyright: (c) 2021 by the authors. Licensee MDPI, Basel, Switzerland. This article is an open access article distributed under the terms and conditions of the Creative Commons Attribution (CC BY) license (https:// creativecommons.org/licenses/by/ $4.0 /)$.

\begin{abstract}
During nuclear accidents, decision-makers need to handle considerable data to take appropriate protective actions to protect people and the environment from radioactive material release. In such scenarios, machine learning can be an essential tool in facilitating the protection action decisions that will be made by decision-makers. By feeding machines software with big data to analyze and identify nuclear accident behavior, types, and the concentrations of released radioactive materials can be predicted, thus helping in early warning and protecting people and the environment. In this study, based on the ground deposition concentration of radioactive materials at different distances offsite in an emergency planning zone (EPZ), we proposed classification and regression models for three severe accidents. The objective of the classification model is to recognize the transient situation type for taking appropriate actions, while the objective of the regression model is to estimate the concentrations of the released radioactive materials. We used the Personal Computer Transient Analyser (PCTRAN) Advanced Power Reactor (APR) 1400 to simulate three severe accident scenarios and to generate a source term released to the environment. Additionally, the Radiological Consequence Analysis Program (RCAP) was used to assess the off-site consequences of nuclear power plant accidents and to estimate the ground deposition concentrations of radionuclides. Moreover, ground deposition concentrations at different distances were used as input data for the classification and regression tree (CART) models to obtain an accident pattern and to establish a prediction model. Results showed that the ground deposition concentration at a near distance from a nuclear power plant is a more informative parameter in predicting the concentration of radioactive material release, while the ground deposition concentration at a far distance is a very informative parameter in identifying accident types. In the regression model, the R-square of the training and test data was 0.995 and 0.994, respectively, showing a mean strong linear relationship between the predicted and actual concentration of radioactive material release. The mean absolute percentage error was found to be $26.9 \%$ and $28.1 \%$ for the training and test data, respectively. In the classification model, the model predicted a scenario (1) of $99.8 \%$ and $98.9 \%$, scenario (2) of $98.4 \%$ and $91.6 \%$, and scenario (3) of $98.6 \%$ and $94.7 \%$ for the training and test data, respectively.
\end{abstract}

Keywords: nuclear emergency; PCTRAN; RCAP; source term estimation; machine learning

\section{Introduction}

Nuclear energy is considered to be one of the cleanest energy sources due to its low emission of greenhouse gases. In addition, it is a baseload power with a steady and huge output unlike other renewable energies, such as solar and wind energies [1]. Throughout the history of nuclear energy, there have been three notorious nuclear accidents: Chernobyl, Three Mile Island (TMI), and Fukushima. Hence, the potential hazards associated with nuclear power plants have been a major concern among people due to the huge amounts of released radioactive materials during nuclear disasters, which significantly affect humans and the environment [2-4]. The identification of nuclear accidents and estimating the 
concentration of radioactive materials released are among the critical issues in nuclear power plant safety [5]. Each type of accident has a unique pattern similar to a human finger print that can help identify it, as each accident has specific symptoms consisting of a set of plant variables [6]. The use of decision support systems (DSSs) is key for supporting the safety and security aspects during nuclear emergency operations. They help the decision maker to recognize accident patterns and to take adequate protection action. DSSs are not only necessary to guarantee the correct choices for safety precautions but also to improve the prevention phase, which is essential in emergency planning systems [7,8]. Artificial intelligence (AI)-based DSSs were developed to reduce human errors in nuclear reactors during abnormal situations. Operator decisions in the control room using DSS to identify the abnormal operating procedure were compared to the original method that operators use in case of abnormal events, which is based on the Abnormal Operating Procedure, and the results revealed that using DSS reduced decision-making time by $25 \%$ and enhanced decision accuracy by $18 \%$. The DSS aided in reducing the quantity of information that operators must consider, thereby increasing the accuracy and speed in the decision-making process [9]. A new machine learning method based on the nearest neighbor theory was applied to classify three types of design-based accidents: a loss of coolant accident (LOCA), a steam generator tube rupture (SGTR), and a main feed water break (MFWBR) in addition to normal operation. Primary water flow rate, steam generator pressure, flow in the rupture, and sub-cooling margin were used as defining plant variables for simulation. The results showed that the ability of a system to identify the accidents [10]. Another study used neural networks to predict the behaviors of a multi-application small light water reactor (MASLWR), where data focusing on the primary system of the reactor and its pressure vessel (onsite data) were collected from 58 different sensors, for example, core heat temperature, coil steam generator temperature, core pressure, and main feedwater flow rate. The neural network was trained by onsite complex data, and the prediction of the MASLWR behaviors demonstrated high accuracy. The predicted data could help decision-makers take prompts and accurate actions during transient situations [11]. Additionally, the deep modifier neural network was used to determine the transient mode in a nuclear reactor over a short period of time. This experiment was validated using 16 physical variables for 13 operational scenarios; 12 postulated accidents and normal operation were simulated for the Angra-2 PWR-type NPP in Brazil. In previous studies, input data were physical variables that existed in the containment of the reactor's onsite parameters, such as the core flow rate, steam generator level, pressurizer pressure, and nuclear power, etc. [6], but these onsite parameters are not always readily available. During the Fukushima accident in 2011, the System for Prediction of Environmental Emergency Dose Information (SPEEDI) failed to assist operators in making sound decisions, and changes in the radionuclide emission intensity with time could not be obtained. The power supply of the onsite instrumentation that provides the release rate to SPEEDI was broken because of the earthquake and tsunami [12]. Therefore, it is challenging to acquire onsite parameters during nuclear emergencies. One of the reasons that led to the increase in the consequences of the Chernobyl accident was that the accident was not initially recognized even though there were indisputable indications [13]. Another reason that gives this study importance is lack of transparency in the information exchange during a nuclear emergency. Most European countries were affected by the Chernobyl disaster, and necessary protective measures were delayed due to an inability to quickly recognize the situation on the ground as well as insufficient information and a lack of transparency [14,15]. Based on ground deposition concentration, which is an offsite parameter, in this study, a machine learning model was proposed to identify the nuclear accident type using the classification and regression tree (CART) model and to estimate the amount of radioactive materials emitted to the environment. In previous literature studies, the accident type classification was mainly based on the internal physical variables of the reactors, such as reactor pressure, mean core temperature, etc. However, this study utilized the ground depositions of radionuclides at different distances outside of reactors. 


\section{Materials and Methods}

The method used in this study is divided into three steps. The first step is to simulate severe accident scenarios using a PCTRAN for an advanced power reactor (PCTRANAPR1400) to generate the source term for each accident. The second step is to use the Radiological Consequence Analysis Program (RCAP) to estimate the consequences of each accident, where the meteorological data and source term are input files for the RCAP software. The third step is to build the CART model using Minitab software. Figure 1 shows a schematic diagram of the methodology used in this study.

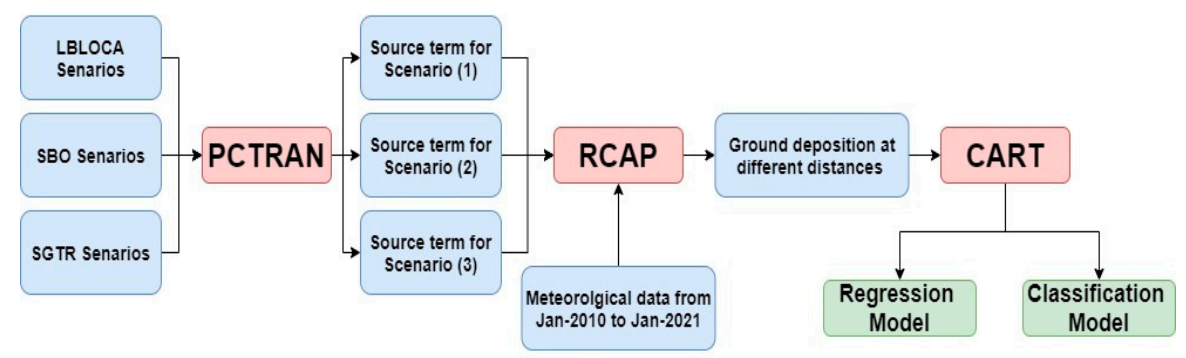

Figure 1. Schematic diagram of the proposed method.

\subsection{Accident Scenarios}

PCTRAN is a simulation tool authorized by the International Atomic Energy Agency (IAEA). It can be used to simulate normal and transient operations, such as design basis accidents and severe accidents, for different types of reactors. In addition, PCTRAN can be used in the emergency response of nuclear power plants. Once an accident is initiated, the in-charge personnel can use the same initial conditions and can simulate the accident on PCTRAN to evaluate its consequences [16]. PCTRAN has been applied by many researchers to conduct various accident analyses, and PCTRAN-BWR models have been used to simulate the scenario of the Fukushima accident based on the IAEA transcript. These models could realistically display the plant behavior and radiological consequences [17]. Positive reactivity added to the core and the change in the thermalhydraulic parameters during the incautious control element withdrawal from the core were studied by the PCTRAN-VVER-1200 model [18]. After the Fukushima accident, the United States started to implement diverse and flexible strategies (FLEX) to prevent and mitigate any possible severe accidents in its reactors. Thus, PCTRAN can be used to assess the effectiveness of FLEX strategies in different reactors and different types of accidents [19]. APR1400 is a pressurized water reactor (PWR) with two coolant loops, and it generates 3983 MW thermal power. Figure 2 shows the main console of PCTRAN-APR1400 and the main components inside the containment, which comprises two vertical steam generators, four reactor coolant pumps, a pressurizer, main and auxiliary feedwater systems, and engineering safety systems. APR1400 was designed and built to withstand design basis accidents (DBAs) using engineering safety features (ESFs) [20]. Generally, such ESFs can mitigate the consequences of design basis accidents by maintaining long-term core cooling as well as the integrity of the containment buildings and by limiting the offsite release of radioactive materials [21]. In this study, we used PCTRAN-APR1400 to calculate the source term for three initial events that contribute greatly to core damage frequency and cause severe accidents: loss of coolant accident (LOCA), station blackout (SBO), and steam generator tube rupture (SGTR) [22]. In all of the accident simulations, the target reached core meltdown, where the engineering safety systems fail to mitigate the consequences of the DBAs. 


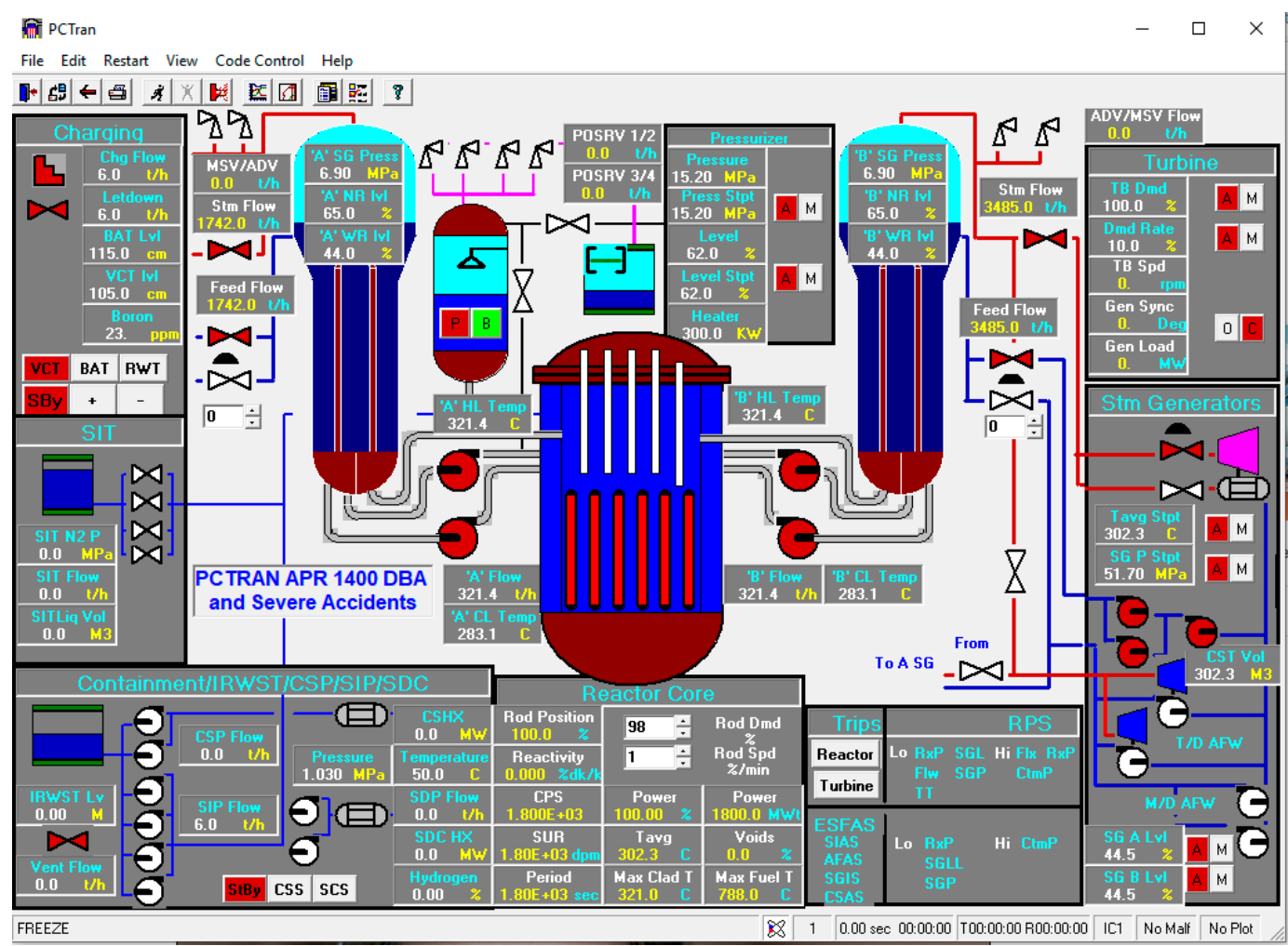

Figure 2. PCTRAN console for the APR1400 nuclear power plant.

\subsubsection{Scenario (1)}

Scenario (1) is a cold leg loss of coolant accident (LOCA) without an Emergency Core Cooling System (ECCS). In APR1400, in the case of LOCA accidents, the safety injection system (SIS) is automatically actuated to keep the reactor core submerged and cooled. In this study, a LOCA in a cold leg was simulated with disabled SIS. While the reactor coolant was discharged through a break, there was no cooling water injection. Following the initiation of the LOCA accident, the reactor instantaneously tripped, and the core was uncovered within a few seconds due to very rapid depressurization. Since no SIS was available in this scenario, the fuel temperature continuously increased. With the increase in the cladding temperature, the interaction between the cladding and steam was accelerated. Shortly after the core was uncovered, the reactor core started to melt [23]. Table 1 explains the summary of the timeline of the cold leg LOCA accident scenario.

Table 1. Cold leg LOCA without the ECCS scenario.

\begin{tabular}{cc}
\hline Time (S) & Sequences \\
\hline $0.0-10.0$ & Run the simulator in steady-state (normal operation) \\
10.5 & All values of safety injection tank (SIT) and SIS pumps are disabled. \\
12.0 & Initiate a cold leg LOCA by selecting Malfunction \# 2 to simulate a 2800 $\mathrm{cm}^{2}$ break [23]. \\
15.5 & Reactor Scram due to containment pressure, Turbine trip \\
17.5 & Spray system on \\
2758.5 & The main steam safety valve (MSSV) fluctuate to adjust the SG pressure \\
3370.0 & Core Collapsed \\
Vessel failed
\end{tabular}

\subsubsection{Scenario (2)}

Scenario (2) is a station blackout (SBO) without auxiliary feed-water systems (AFWs). SBO entails the complete loss of alternating current (AC) electrical power to a nuclear power plant, where both the offsite AC and onsite emergency system powers are lost. 
Due to the decay heat after the shutdown, long-term SBO might eventually lead to severe accidents in nuclear reactors. In the simulation, after the initiation of SBO, the reactor's trip signal was generated due to the low coolant flow rate. The reactor pressure increased since the reactor coolant pump stopped and caused an increase in the reactor coolant temperature. On the secondary side of the reactor's steam generators, since the main feedwater pumps stopped and there was no steam flow, the pressure increased and was slowly discharged through the MSSVs. Despite the reactor being shut down and the chain reaction being stopped by the insertion of the control elements, the decay heat increased the reactor's coolant temperature, and the reactor pressure increased until the pilot-operated safety relief valve (POSRV) opened to release the excess pressure. Even after the opening of the POSRV, the reactor's coolant was continuously heated up, and heat was transferred to the steam generator, as the main feedwater system was stopped due to the SBO and unfunctional AFW. The reactor pressure was maintained high enough to keep the relief valve open. As a result, the reactor's coolant liquid volume decreased, and the reactor core was uncovered [24]. Table 2 shows the summary of the timeline of the station blackout scenario.

Table 2. Station blackout without auxiliary feed-water systems (AFWs) scenario.

\begin{tabular}{cc}
\hline Time (S) & Sequences \\
\hline $0.0-10.0$ & Run the simulator in steady-state (normal operation) \\
10.5 & Manually disable the turbine-driven auxiliary feed-water pump. \\
11.5 & Malfunction \# 13 Fraction $=00.0 \%$ \\
15.5 & Reactor Scram, Turbine trip \\
6067.0 & MSS fluctuate to adjust the SG pressure \\
6849.5 & POSRV fluctuate to adjust the PV pressure \\
$13,051.0$ & MSIV and FWIV are closed \\
$13,860.0$ & Core Collapsed \\
\end{tabular}

\subsubsection{Scenario (3)}

Scenario (3) is a steam generator tube rupture (SGTR) concurrent with SBO. SGTR is a postulated accident. It is one of the DBAs that the APR1400 reactor can withstand. In this scenario, SGTR occurred at the same time as SBO. The double-ended rupture of the steam generator's U-tube led to reactor tripping, and a concurrent turbine trip immediately occurred on a high level of the steam generator. No time delay between the turbine trip and SBO was assumed in the analysis [20]. Table 3 shows the summary of the timeline of the SGTR concurrent with the SBO scenario.

Table 3. SGTR Concurrent with the SBO scenario.

\begin{tabular}{cc}
\hline Time (S) & Sequences \\
\hline $0.0-10.0$ & Run the simulator in steady-state (normal operation) \\
11.0 & Malfunction \# 11 Fraction SGTR \\
Malfunction \# 13 Fraction SBO \\
12.5 & Reactor Scram, Turbine trip \\
16.5 & POSRV fluctuate to adjust the PV pressure \\
52.0 & All MFW Pumps trip \\
2223.5 & MSSV fluctuate to adjust the SG pressure \\
$15,914.5$ & Core Collapsed \\
$16,745.0$ & Vessel failed \\
\hline
\end{tabular}

\subsection{Atmospheric Dispersion Model}

RCAP is new software developed by the Korea Atomic Energy Research Institute (KAERI) to perform Level 3 probabilistic safety assessments (PSAs), which estimate the off-site consequences of nuclear power plant accidents. RCAP assesses the impacts of the 
release of radioactive materials to the environment. The basic physical model of RCAP for evaluating the diffusion and transport of radioactive materials in the atmosphere and their deposition on surfaces is the Gaussian plume segment model. Equation (1) is used in RCAP to calculate the plume centerline air concentration, and the ground level concentration from the time plume segment is released until the vertical distribution segment becomes uniform with inversion layer (mixing height).

$$
\begin{aligned}
C(x, y, z)=\frac{Q}{2 \pi \sigma_{y}(x) \sigma_{z} u} \times & \left(\exp \left\{-\frac{1}{2}\left[\frac{z-H}{\sigma_{z}}\right]^{2}\right\}+\exp \left\{-\frac{1}{2}\left[\frac{z+H}{\sigma_{z}}\right]^{2}\right\}\right) \\
+\sum_{n=1}^{n}\left(\exp \left\{-\frac{1}{2}\left[\frac{z-H-2 n l}{\sigma_{z}}\right]^{2}\right\}+\exp \left\{-\frac{1}{2}\left[\frac{z+H-2 n l}{\sigma_{z}}\right]^{2}\right\}+\exp \left\{-\frac{1}{2}\left[\frac{z+H+2 n l}{\sigma_{z}}\right]^{2}\right\}\right. & \left.+\exp \left\{-\frac{1}{2}\left[\frac{z-H+2 n l}{\sigma_{z}}\right]^{2}\right\}\right)
\end{aligned}
$$

where $C$ is time-integrated atmospheric concentration $(\mathrm{Ci}-\mathrm{s}) /\left(\mathrm{m}^{3}\right)$. $Q$ is the source term (Ci). $H$ is the effective release height (m). $x$ is the downwind distance $(\mathrm{m}), y$ is the crosswind distance $(\mathrm{m}), z$ is the vertical axis distance $(\mathrm{m}) . \sigma_{y}$ is the standard deviation of the integrated concentration distribution in the crosswind direction $(\mathrm{m}), \sigma_{z}$ is the standard deviation of the integrated concentration distribution in the vertical direction $(\mathrm{m}), u$ is the average wind speed at the effective release height, and $l$ is the height of the inversion layer (m). The values depend on the downwind distance, $x$.

\subsubsection{Source Term}

Source term is an input file to the RCAP code. In this study, the source term was calculated by PCTRAN APR1400 for each scenario. The number of radionuclides generated by PCTRAN was 52 radioisotopes for each scenario. The radionuclides with half-lives less than 1 day were ignored because of their low contributions to ground deposition due to their fast decay. However, some radionuclides with halflives less than 1 day were considered in the calculation because their daughters had high halflives. Table 4 shows the radionuclides and their daughters, which were produced by decay, and their activity in Bq

\begin{tabular}{|c|c|c|c|c|c|c|c|}
\hline \multirow{2}{*}{ No } & \multirow{2}{*}{$\begin{array}{l}\text { Radionuclide } \\
\text { Name }\end{array}$} & \multicolumn{3}{|c|}{ Half-Life (Days) } & \multicolumn{3}{|c|}{ Activity (Bq) } \\
\hline & & $T_{1 / 2}(1)$ & Daughter & $\mathrm{T}_{1 / 2}(2)$ & Scenario (1) & Scenario (2) & Scenario (3) \\
\hline 1 & ${ }^{85} \mathrm{Kr}$ & 3912.80 & \multirow{4}{*}{$\begin{array}{l}{ }^{85} \mathrm{Kr} \\
{ }^{87} \mathrm{Rb}\end{array}$} & \multirow{4}{*}{$\begin{array}{c}3912.80 \\
1.79 \times 10^{13}\end{array}$} & $1.05 \times 10^{11}$ & $2.00 \times 10^{12}$ & $1.21 \times 10^{12}$ \\
\hline 2 & ${ }^{85} \mathrm{~m}_{\mathrm{Kr}}$ & 0.19 & & & $9.23 \times 10^{11}$ & $2.10 \times 10^{13}$ & $1.08 \times 10^{13}$ \\
\hline 3 & ${ }^{87} \mathrm{Kr}$ & 0.05 & & & $1.39 \times 10^{11}$ & $8.14 \times 10^{11}$ & $3.22 \times 10^{11}$ \\
\hline 4 & ${ }^{133} \mathrm{Xe}$ & 5.25 & & & $7.53 \times 10^{12}$ & $2.65 \times 10^{14}$ & $1.48 \times 10^{14}$ \\
\hline 5 & ${ }^{135} \mathrm{Xe}$ & 0.38 & \multirow{10}{*}{$\begin{array}{l}{ }^{135} \mathrm{Cs} \\
{ }^{135} \mathrm{Cs} \\
{ }^{135} \mathrm{Xe}\end{array}$} & \multirow{2}{*}{$\begin{array}{c}8.40 \times 10^{8} \\
8.40 \times 10^{8} \\
0.37875\end{array}$} & $1.30 \times 10^{12}$ & $3.91 \times 10^{13}$ & $2.05 \times 10^{13}$ \\
\hline 6 & ${ }^{135 m} X e$ & 0.01 & & & $6.71 \times 10^{11}$ & $1.00 \times 10^{11}$ & $5.60 \times 10^{10}$ \\
\hline 7 & ${ }^{134} \mathrm{Cs}$ & 752.63 & & & $3.08 \times 10^{11}$ & $1.24 \times 10^{13}$ & $6.91 \times 10^{12}$ \\
\hline 8 & ${ }^{136} \mathrm{Cs}$ & 13.10 & & & $7.99 \times 10^{09}$ & $3.20 \times 10^{11}$ & $1.77 \times 10^{11}$ \\
\hline 9 & ${ }^{137} \mathrm{Cs}$ & $10,950.0$ & & & $7.88 \times 10^{11}$ & $3.18 \times 10^{13}$ & $1.77 \times 10^{13}$ \\
\hline 10 & ${ }^{86} \mathrm{Rb}$ & 18.66 & & & $3.94 \times 10^{08}$ & $1.58 \times 10^{10}$ & $8.76 \times 10^{09}$ \\
\hline 11 & ${ }^{140} \mathrm{Ba}$ & 12.74 & & & $2.02 \times 10^{11}$ & $8.09 \times 10^{12}$ & $4.49 \times 10^{12}$ \\
\hline 12 & ${ }^{89} \mathrm{Sr}$ & 50.50 & & & $3.27 \times 10^{11}$ & $1.32 \times 10^{13}$ & $7.31 \times 10^{12}$ \\
\hline 13 & ${ }^{90} \mathrm{Sr}$ & $10,628.8$ & & & $5.54 \times 10^{11}$ & $2.24 \times 10^{13}$ & $1.24 \times 10^{13}$ \\
\hline 14 & ${ }^{131} \mathrm{I}$ & 8.04 & & & $2.01 \times 10^{11}$ & $1.17 \times 10^{13}$ & $7.22 \times 10^{12}$ \\
\hline 15 & ${ }^{133} \mathrm{I}$ & 0.87 & \multirow[t]{2}{*}{$\begin{array}{c}{ }^{133 m} \mathrm{Xe} \\
{ }^{133} \mathrm{Xe}\end{array}$} & $\begin{array}{c}2.19 \\
5.2475\end{array}$ & $4.23 \times 10^{11}$ & $2.23 \times 10^{13}$ & $1.35 \times 10^{13}$ \\
\hline 16 & ${ }^{127 \mathrm{~m}} \mathrm{Te}$ & 109.00 & & & $8.51 \times 10^{9}$ & $3.43 \times 10^{11}$ & $1.90 \times 10^{11}$ \\
\hline
\end{tabular}
for each scenario.

Table 4. Output source term calculated by PCTRAN for each accident scenario. 
Table 4. Cont.

\begin{tabular}{|c|c|c|c|c|c|c|c|}
\hline \multirow{2}{*}{ No } & \multirow{2}{*}{$\begin{array}{l}\text { Radionuclide } \\
\text { Name }\end{array}$} & \multicolumn{3}{|c|}{ Half-Life (Days) } & \multicolumn{3}{|c|}{ Activity (Bq) } \\
\hline & & $\mathrm{T}_{1 / 2}(\mathbf{1})$ & Daughter & $T_{1 / 2}(2)$ & Scenario (1) & Scenario (2) & Scenario (3) \\
\hline 17 & ${ }^{129} \mathrm{Te}$ & 0.05 & ${ }^{129} \mathrm{I}$ & $5.73 \times 10^{9}$ & $1.07 \times 10^{10}$ & $4.30 \times 10^{11}$ & $2.39 \times 10^{11}$ \\
\hline 18 & ${ }^{129 \mathrm{~m}} \mathrm{Te}$ & 33.60 & & & $1.64 \times 10^{10}$ & $6.61 \times 10^{11}$ & $3.67 \times 10^{11}$ \\
\hline 19 & ${ }^{131 \mathrm{~m}} \mathrm{Te}$ & 1.25 & $\begin{array}{c}{ }^{131} \mathrm{I} \\
{ }^{131} \mathrm{Te}\end{array}$ & 8.04 & $2.54 \times 10^{10}$ & $9.24 \times 10^{11}$ & $5.16 \times 10^{11}$ \\
\hline 20 & ${ }^{132} \mathrm{Te}$ & 3.26 & & & $1.46 \times 10^{09}$ & $5.67 \times 10^{10}$ & $3.13 \times 10^{10}$ \\
\hline 21 & ${ }^{103} \mathrm{Ru}$ & 39.28 & & & $5.97 \times 10^{11}$ & $2.40 \times 10^{13}$ & $1.33 \times 10^{13}$ \\
\hline 22 & ${ }^{106} \mathrm{Ru}$ & 368.20 & & & $6.71 \times 10^{11}$ & $2.71 \times 10^{13}$ & $1.50 \times 10^{13}$ \\
\hline 23 & ${ }^{95} \mathrm{Nb}$ & 35.15 & & & $9.91 \times 10^{11}$ & $3.99 \times 10^{13}$ & $2.22 \times 10^{13}$ \\
\hline 24 & ${ }^{58} \mathrm{Co}$ & 70.80 & & & $8.93 \times 10^{8}$ & $3.60 \times 10^{10}$ & $2.00 \times 10^{10}$ \\
\hline 25 & ${ }^{60} \mathrm{Co}$ & 1923.92 & & & $1.45 \times 10^{10}$ & $5.86 \times 10^{11}$ & $3.25 \times 10^{11}$ \\
\hline 26 & ${ }^{99} \mathrm{Mo}$ & 2.75 & & & $5.79 \times 10^{8}$ & $2.24 \times 10^{10}$ & $1.24 \times 10^{10}$ \\
\hline 27 & ${ }^{99 \mathrm{~m}} \mathrm{Tc}$ & 0.25 & ${ }^{99} \mathrm{Tc}$ & $7.71 \times 10^{7}$ & $5.56 \times 10^{8}$ & $2.15 \times 10^{10}$ & $1.19 \times 10^{10}$ \\
\hline 28 & ${ }^{141} \mathrm{Ce}$ & 32.50 & & & $5.15 \times 10^{11}$ & $2.07 \times 10^{13}$ & $1.15 \times 10^{13}$ \\
\hline 29 & ${ }^{144} \mathrm{Ce}$ & 284.30 & & & $1.03 \times 10^{12}$ & $4.15 \times 10^{13}$ & $2.31 \times 10^{13}$ \\
\hline 30 & ${ }^{239} \mathrm{~Np}$ & 2.36 & & & $2.17 \times 10^{9}$ & $8.37 \times 10^{10}$ & $4.61 \times 10^{10}$ \\
\hline 31 & ${ }^{238} \mathrm{Pu}$ & $32,025.1$ & & & $1.76 \times 10^{10}$ & $7.10 \times 10^{11}$ & $3.94 \times 10^{11}$ \\
\hline 32 & ${ }^{239} \mathrm{Pu}$ & $8,783,725.0$ & & & $1.76 \times 10^{10}$ & $7.10 \times 10^{11}$ & $3.94 \times 10^{11}$ \\
\hline 33 & ${ }^{240} \mathrm{Pu}$ & $2,386,005.0$ & & & $5.07 \times 10^{9}$ & $2.05 \times 10^{11}$ & $1.14 \times 10^{11}$ \\
\hline 34 & ${ }^{241} \mathrm{Pu}$ & 5256.00 & & & $8.94 \times 10^{11}$ & $3.61 \times 10^{13}$ & $2.00 \times 10^{13}$ \\
\hline 35 & ${ }^{95} \mathrm{Zr}$ & 63.98 & & & $7.57 \times 10^{11}$ & $3.05 \times 10^{13}$ & $1.69 \times 10^{13}$ \\
\hline 36 & ${ }^{241} \mathrm{Am}$ & $157,753.00$ & & & $1.12 \times 10^{10}$ & $4.53 \times 10^{11}$ & $2.52 \times 10^{11}$ \\
\hline 37 & ${ }^{242} \mathrm{Cm}$ & 162.80 & & & $5.66 \times 10^{10}$ & $2.28 \times 10^{12}$ & $1.27 \times 10^{12}$ \\
\hline 38 & ${ }^{244} \mathrm{Cm}$ & 6610.15 & & & $8.86 \times 10^{9}$ & $3.57 \times 10^{11}$ & $1.98 \times 10^{11}$ \\
\hline 39 & ${ }^{140} \mathrm{La}$ & 1.68 & & & $2.33 \times 10^{11}$ & $9.31 \times 10^{12}$ & $5.16 \times 10^{12}$ \\
\hline 40 & ${ }^{147} \mathrm{Nd}$ & 10.98 & & & $6.00 \times 10^{10}$ & $2.40 \times 10^{12}$ & $1.33 \times 10^{12}$ \\
\hline 41 & ${ }^{143} \mathrm{Pr}$ & 13.56 & & & $2.12 \times 10^{11}$ & $8.49 \times 10^{12}$ & $4.71 \times 10^{12}$ \\
\hline 42 & ${ }^{90} \mathrm{Y}$ & 2.67 & & & $5.58 \times 10^{11}$ & $2.25 \times 10^{13}$ & $1.25 \times 10^{13}$ \\
\hline 43 & ${ }^{91} \mathrm{Y}$ & 58.51 & & & $4.60 \times 10^{11}$ & $1.85 \times 10^{13}$ & $1.03 \times 10^{13}$ \\
\hline
\end{tabular}

\subsubsection{Meteorological Data}

The consequences of the emitted radioactive materials were evaluated based on atmospheric meteorological data. The Gaussian plume segment model typically reads data from a file containing 1 year's worth of observed hourly meteorological data (8760 observations). These data include wind direction, wind speed $(\mathrm{m} / \mathrm{s})$, stability class $(\mathrm{A} \sim \mathrm{G})$, precipitation $(\mathrm{mm} / \mathrm{h})$, and mixing height $(\mathrm{m})$. The meteorological data were obtained from the Korean Meteorological Agency (KMA), and it was for Ulsan city from 1 January 2010 to 1 January 2021 (11 years). For each year, the RCAP code was run for the three accident scenarios.

\subsection{Classification and Regression Tree (CART) Model}

The RCAP results, which will be presented in the results section, were used as input data for the CART model. The RCAP output was the ground deposition concentration $\left(\mathrm{Bq} / \mathrm{m}^{2}\right)$ per radionuclide in the source term, including the daughters coming from the decay. The ground deposition was calculated from the center of the emission of the radionuclides to the end of the emergency planning zone (EPZ), which was extended to $30 \mathrm{~km}$ around the accident site. We divided the EPZ area into 30 different rings, and increased each ring's radius by $1 \mathrm{~km}$. The ground deposition- 1 represents the average value of radionuclide concentration from $0 \mathrm{~km}$ to $1 \mathrm{~km}$. A total of 34 parameters were used in the CART model for classification and regression as follows:

1. Accident type;

2. Radionuclide nam;e

3. Activity of source term $(\mathrm{Bq})$;

4. Year of the meteorological data used in the simulation; 
5. Ground deposition data from the center of the emission of the radionuclides to the emergency planning zone that represent 30 parameters.

\subsubsection{CART Classification}

The Minitab software performs classifications using a decision tree model to create a tree for binomial or multinomial categorical responses with many categorical or continuous predictors. The proposed model in this study is considered multinomial because we simulated three accidents. The number of predictors used was 34 . Table 5 shows the method and model summary of the data used.

Table 5. Summary of the data used in the classification model.

\begin{tabular}{|c|c|c|c|c|}
\hline \multicolumn{5}{|c|}{ Method } \\
\hline Prior probabilities & \multicolumn{4}{|c|}{ Same for all classes } \\
\hline Model validation & \multicolumn{4}{|c|}{$70 / 30 \%$ training/test sets } \\
\hline Rows used & \multicolumn{4}{|c|}{1815} \\
\hline No. predicators & \multicolumn{4}{|c|}{34} \\
\hline \multicolumn{5}{|c|}{ Multinomial Response Information } \\
\hline Accident type & No. training data & Percentage of training data & No. test data & Percentage of test data \\
\hline Scenario (1) & 415 & 32.7 & 190 & 34.9 \\
\hline Scenario (2) & 438 & 34.5 & 167 & 30.7 \\
\hline Scenario (3) & 418 & 32.9 & 187 & 34.4 \\
\hline ALL & 1271 & 100.0 & 544 & 100.0 \\
\hline
\end{tabular}

\subsubsection{CART Regression}

Regression in the Minitab software was performed using a decision tree model to create a tree for a continuous response with many categorical or continuous predictors. In general, CART regression illustrates important patterns and relationships between continuous responses and important predictors within highly complicated data without using parametric methods. Table 6 shows a summary of the used method and the data in the regression model.

Table 6. Summary of the data used in the regression model.

\begin{tabular}{ccc}
\hline & Method \\
\hline Node splitting & \multicolumn{2}{c}{ Least squared error } \\
Model validation & $70 / 30 \%$ training/test sets \\
Rows used & \multicolumn{2}{c}{315} \\
No. predicators & \multicolumn{2}{c}{ Test data } \\
\hline \multicolumn{3}{c}{ Statistical Response Information } \\
\hline Training data & $544(30 \%)$ \\
Number of data & $1271(70 \%)$ & $6.94748 \times 10^{12}$ \\
Mean & $8.54968 \times 10^{12}$ & $4.23000 \times 10^{11}$ \\
Median & $3.94000 \times 10^{11}$ & $1.89444 \times 10^{13}$ \\
Standard deviation & $2.76247 \times 10^{13}$ & $2.65000 \times 10^{14}$ \\
Maximum & $2.65000 \times 10^{14}$ &
\end{tabular}

\section{Results and Discussion}

\subsection{RCAP Results}

The ground deposition concentration was calculated for the three accidents scenarios at different distances and with 11 years of meteorological data. The total number of runs was 33, and total 1815 pieces of data were generated. We will present the results of one year, 2020, to explain the ground deposition behavior. Figure 3 explains the deposition of the radionuclides that were released from the three accidents scenarios at different 
distances. The radionuclide concentration has a gradient scale. We can see three groups of concentration. The high ground deposition concentration cluster started with ${ }^{88} \mathrm{Rb}$ and ended at ${ }^{143} \mathrm{Pr}$. The inter-medium ground deposition concentration group started at ${ }^{132} \mathrm{I}$ and ended at ${ }^{240} \mathrm{Pu}$. The low ground deposition group concentration started at ${ }^{239} \mathrm{Nb}$ and ended at ${ }^{86} \mathrm{Rb}$. The behaviors of radioactive materials are the same in the three accidents. The concentration decreased with increasing distance. However, the concentration of the radionuclides is different from accident to another. The three accident sites have three clusters, but the start values and end values for each group are different from one accident to another. From this point of view, each accident has a unique symptom. The accident identification could be completed using these symptoms. These data have been fed to the CART model to predict the amount of radioactive material release to classify the accident type.

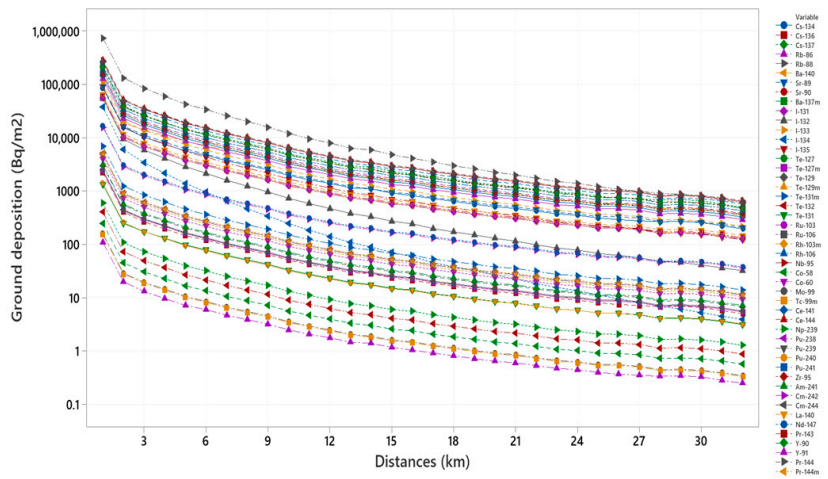

(a)

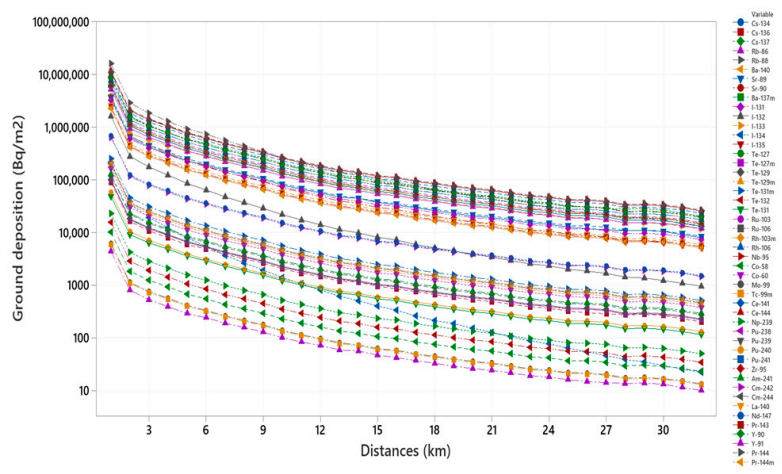

(b)
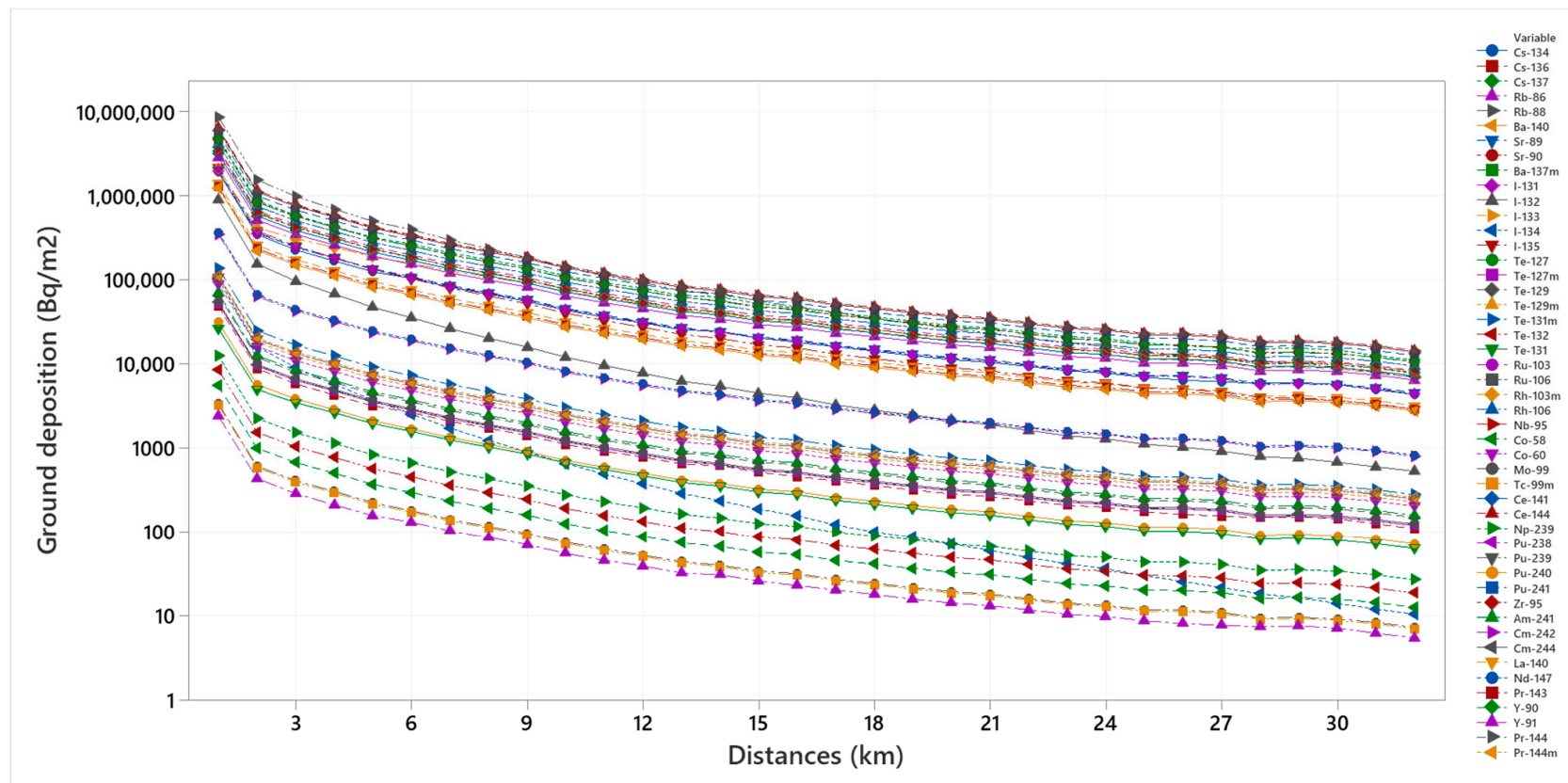

(c)

Figure 3. Illustration of the different of ground deposition concentrations for the radionuclides in the three accidents scenarios for the 2020 meteorological data. (a) The ground deposition for the radionuclides released at different distances for Scenario 1, (b) the ground deposition for the radionuclides released at different distances for Scenario 2, and (c) the ground deposition for the radionuclides released at different distances for Scenario 3. 


\subsection{Classification}

Table 7 shows a confusion matrix for the training and test data. It summarizes the performance of the classification model and gives a better idea of the right classification model and the number of misclassifications made by it.

Table 7. Confusion matrix of the classification model for the training and test data.

\begin{tabular}{cccccc}
\hline \multirow{2}{*}{ Actual Class } & \multicolumn{5}{c}{ Predicted Class (Training Data) } \\
\cline { 2 - 6 } & Count & Scenario (1) & Scenario (2) & Scenario (3) & Precision (\%) \\
\hline Scenario (1) & 415 & $\mathbf{4 1 4}$ & 1 & 0 & 99.8 \\
Scenario (2) & 438 & 0 & $\mathbf{4 3 1}$ & 7 & 98.4 \\
Scenario (3) & 418 & 6 & 4 & $\mathbf{4 0 8}$ & $\mathbf{9 7 . 6}$ \\
All & 1271 & 420 & 436 & 415 & 98.6 \\
\hline & \multicolumn{5}{c}{ Predicted Class (Test Data) } \\
Actual Class & Count & Scenario (1) & Scenario (2) & Scenario (3) & Precision (\%) \\
\cline { 2 - 6 } & 190 & $\mathbf{1 8 8}$ & 0 & 2 & 98.9 \\
Scenario (1) & 167 & 3 & $\mathbf{1 5 3}$ & 11 & 91.6 \\
Scenario (2) & 187 & 3 & 10 & $\mathbf{1 7 4}$ & 93.0 \\
Scenario (3) & 544 & 194 & 163 & 187 & $\mathbf{9 4 . 7}$ \\
All & \multicolumn{5}{c}{}
\end{tabular}

The confusion matrix shows that the classification model predicted 414/415 of Scenario (1) in the training data and misclassified 1. For the test data, the model predicted 188/190 of Scenario (1) and misclassified 2 cases. For Scenario (2), the model predicted 431/438 cases and misclassified 7 cases in the training data. For the Scenario (2) test data, the model predicted 153/167 and misclassified 14 cases. For Scenario (3), the model predicted 408/418 and misclassified 10 cases for the training data. For the Scenario (3) test data, the model predicted 174/187 and misclassified 13 cases. The average precision of the correct values in the training data was $98.6 \%$, while that of the correct values in the test data was $94.7 \%$. Figure 4 shows a representative graph of the receiver operating characteristic curves (ROC) with the area under the curve (AUC). These curves explain the relation between the true positive rate (sensitivity) and false positive rate (1-specificity). AUC is the probability that the classification model ranks a random positive. It provides a total performance measure across all of the possible classification thresholds. In accident scenario (1), the AUC is 0.99 for the training data and 0.98 for the test data. In accident scenario (2), the AUC is 0.99 for the training data and 0.95 for the test data. In accident scenario (3), the AUC is 0.99 for the training data and 0.95 for the test data.

\subsection{Regression}

Figure 5 is a scatterplot that shows the actual response values on the $x$-axis and the predicted response values on the $y$-axis. The green line represents the equality of the actual values and the predicted values. When the actual values and the predicted values are equal, the prediction accuracy is very high. In this scatterplot, the points for the training and test data sets show similar patterns. This similarity suggests that the performance of the tree on the new data is close to the performance of the tree on the training data. The R-square is 0.998 and 0.994 for the training data and test data, respectively. This signifies a strong positive linear relationship between the predicted data and the real data. The mean absolute percentage error is $26.9 \%$ for the training data and $28.1 \%$ for the test data. 


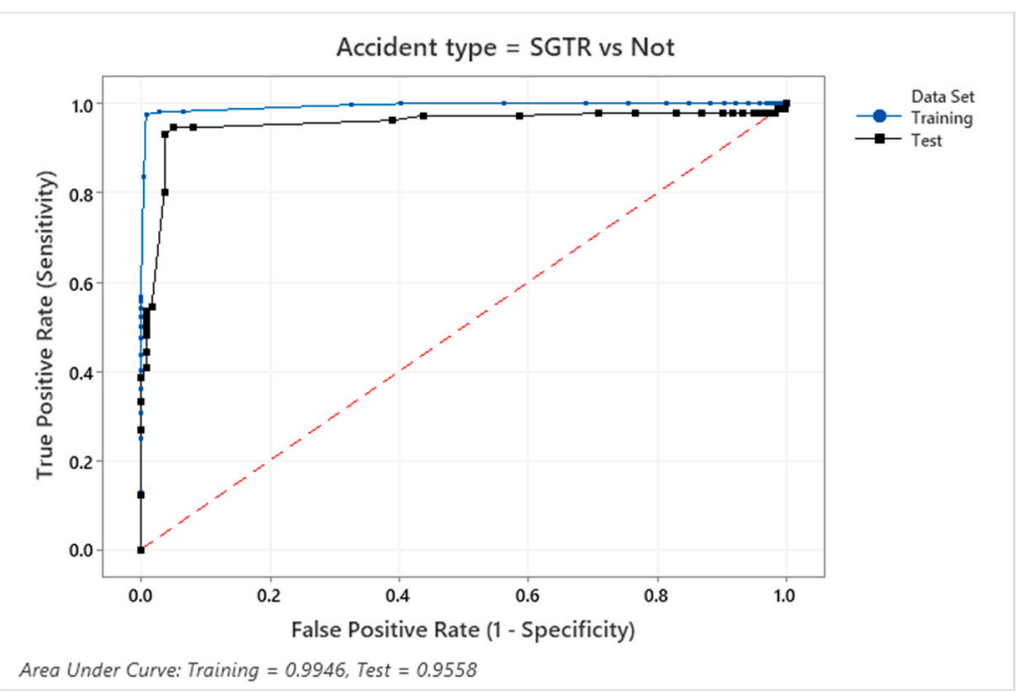

Figure 4. Representative ROC curve for the scenario (3) accident with AUC values. The blue line is the training data set, and the black line is the test data set.

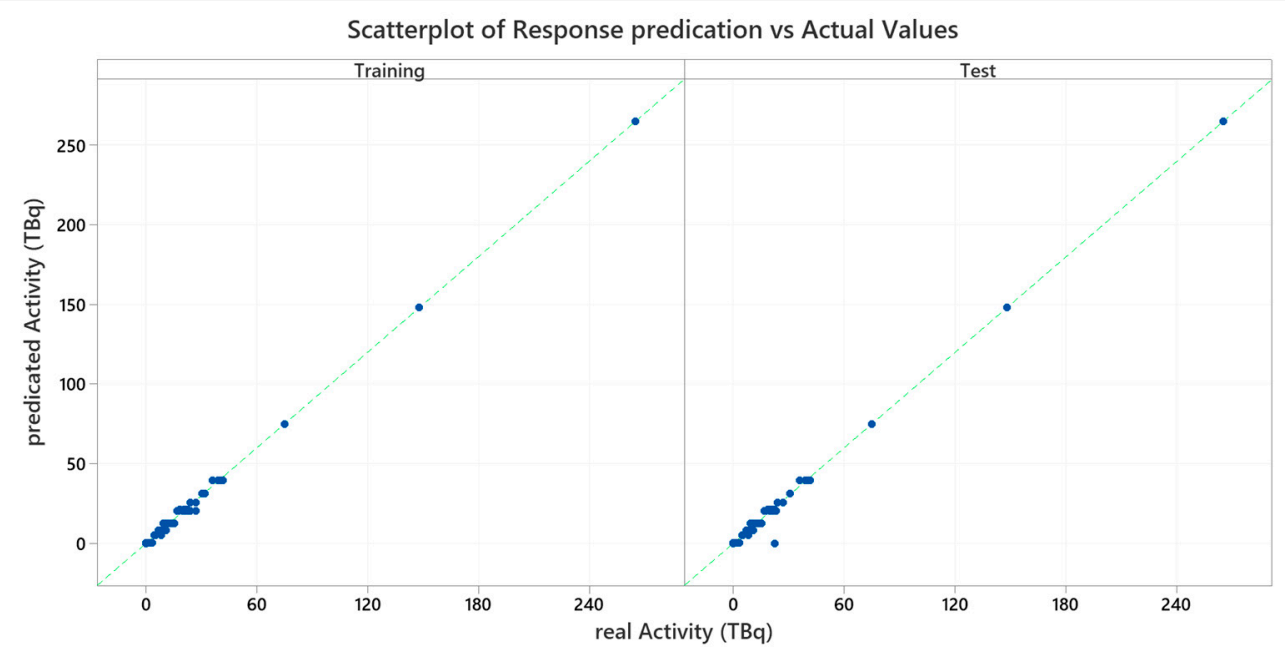

Figure 5. Scatterplot between the real value of the radionuclide activity in $\mathrm{TBq}$ and the predicted values of the radionuclide activity in $\mathrm{TBq}$ for the training data set and the test data.

\subsection{Importance of Variables}

Table 8 illustrates the relative importance of the top variables to determine which predictors are the most important variables for both models. In the classification model, ground deposition at long distances is more informative than ground deposition at short distances in accident classification. This is because the concentration of radioactive materials is high at short distances, making the accident pattern unclear, whereas at great distances, the concentration is low, and the accident pattern is evident. In the regression model, however, ground deposition at short distances is more relevant than ground deposition at long distances in estimating radionuclide concentration. This is due to the fact that the concentration of radioactive elements is high at close distances and decreases with distance, as seen in Figure 3. As a result, for predicting the activity of radioactive material discharged, near distances are more informative in the regression model. 
Table 8. Relative variable importance of classification and regression models.

\begin{tabular}{cclc}
\hline \multicolumn{2}{c}{ Classification Model } & \multicolumn{1}{c}{ Regression Model } & \multicolumn{1}{c}{ Variables } \\
\hline Variables & Relative Importance (\%) & Relative Importance (\%) \\
\hline Ground deposition at $19 \mathrm{~km}$ & 100 & Ground deposition at $2 \mathrm{~km}$ \\
Ground deposition at $20 \mathrm{~km}$ & 99.5 & Ground deposition at $1 \mathrm{~km}$ \\
Ground deposition at $21 \mathrm{~km}$ & 96 & Ground deposition at $3 \mathrm{~km}$ \\
Ground deposition at $22 \mathrm{~km}$ & 93.9 & Ground deposition at $4 \mathrm{~km}$ \\
Ground deposition at $23 \mathrm{~km}$ & 91.4 & Ground deposition at $5 \mathrm{~km}$ \\
Ground deposition at $18 \mathrm{~km}$ & 72.8 & Ground deposition at $6 \mathrm{~km}$ \\
Ground deposition at $17 \mathrm{~km}$ & 65.2 & Ground deposition at $7 \mathrm{~km}$ & 99.5 \\
Ground deposition at $24 \mathrm{~km}$ & 64.6 & Ground deposition at $8 \mathrm{~km}$ & 99 \\
Radionuclide type & 62.7 & Ground deposition at $10 \mathrm{~km}$ & 97.7 \\
\hline
\end{tabular}

Moreover, the importance of ground deposition at $2 \mathrm{~km}$ is equal to that at $1 \mathrm{~km}$. However, the ground deposition rank at $2 \mathrm{~km}$ is higher than that at $1 \mathrm{~km}$. The reason is the elevated emission of the radioactive materials. The reactor building height was considered to be $50 \mathrm{~m}$, and the season mixing height was considered in the meteorological file.

\section{Conclusions}

Off-site parameters can be the eye through which decision-makers can recognize what happens during a nuclear emergency when onsite parameters are not available. Machine learning is an effective approach in nuclear emergency management. It can help decision-makers take suitable protection actions and early decisions to protect people and the environment from the emissions of radioactive materials in the case of nuclear emergencies. In this study, we used the ground deposition of radioactive material in an EPZ to classify three types of severe accidents: LOCA without ECCS, SBO without AFWS, and SGTR concurrent with SBO, and predicted the concentration of radioactive materials released. The three scenarios can be classified at level 7 of the International Nuclear and Radiological Event Scale (INES), where significant radioactive materials are released into the environment along with their subsequent health and environmental impacts that require the initiation of public protective actions at an earlier stage in the event of nuclear emergency. These accidents were simulated by PCTRAN-APR1400 to estimate the amount of radioactive materials that would be released in each accident. The output of PCTRANAPR1400 was the source term that was used as input for the RCAP for it to calculate the offsite consequences of the three accidents. The ground depositions were the offsite parameters, and they were calculated using the RCAP software. The results of the RCAP indicated that each accident has a unique symptom that distinguishes it from the others. Based on that, machine learning models were created using the Minitab software based on the ground depositions at different distances. The average precision of the classification model was $98.6 \%$ for the training data and $94.7 \%$ for the test data. The obtained high precision value means that the classification model could distinguish between these three accidents using the ground deposition values. The R-square in the regression model was 0.995 for the training data and 0.994 for the test data. The high R-square value provided an indication of the strong linear relationship between the predicted radioactive material release and the real radioactive material release. From the relative variable importance in Table 8, we could conclude that the ground deposition at short distances is more informative than that at long distances in the prediction of the concentration of radioactive materials. However, in the relative variable importance graph for accident classification, the ground deposition at farther distances is more informative than that at shorter distances.

Author Contributions: Conceptualization, A.A.E.-H. and J.K.; methodology, A.A.E.-H. and J.K.; investigation, A.A.E.-H. and J.K.; resources, J.K.; data curation, A.A.E.-H.; writing-original draft preparation, A.A.E.-H.; writing-review and editing, A.A.E.-H. and J.K.; supervision, J.K.; funding acquisition, J.K. All authors have read and agreed to the published version of the manuscript. 
Funding: This research was supported by the National Research Foundation of Korea (NRF) grant funded by the Korean government, the Ministry of Science and ICT (No. NRF-2020M2A8A4022526), and by the Nuclear Safety Research Program through the Korea Foundation of Nuclear Safety (KoFONS) using the financial resources granted by the Nuclear Safety and Security Commission (NSSC) of the Republic of Korea (No. 1805018). This research was also funded by the 2021 Research Fund of the KEPCO International Nuclear Graduate School (KINGS), the Republic of Korea.

Institutional Review Board Statement: Not applicable.

Informed Consent Statement: Not applicable.

Data Availability Statement: Data are available upon request.

Conflicts of Interest: The authors declare that there are no conflict of interest.

\section{References}

1. Roth, M.B.; Jaramillo, P. Going nuclear for climate mitigation: An analysis of the cost effectiveness of preserving existing US nuclear power plants as a carbon avoidance strategy. Energy 2017, 131, 67-77. [CrossRef]

2. Kortov, V.; Ustyantsev, Y. Chernobyl accident: Causes, consequences and problems of radiation measurements. Radiat. Meas. 2013, 55, 12-16. [CrossRef]

3. Steinhauser, G.; Brandl, A.; Johnson, T.E. Comparison of the Chernobyl and Fukushima nuclear accidents: A review of the environmental impacts. Sci. Total Environ. 2014, 470, 800-817. [CrossRef] [PubMed]

4. Yasunari, T.J.; Stohl, A.; Hayano, R.S.; Burkhart, J.F.; Eckhardt, S.; Yasunari, T. Cesium-137 deposition and contamination of Japanese soils due to the Fukushima nuclear accident. Proc. Natl. Acad. Sci. USA 2011, 108, 19530-19534. [CrossRef] [PubMed]

5. $\quad$ Ling, Y.; Yue, Q.; Huang, T.; Shan, Q.; Hei, D.; Zhang, X.; Jia, W. Multi-nuclide source term estimation method for severe nuclear accidents from sequential gamma dose rate based on a recurrent neural network. J. Hazard. Mater. 2021, 414, 125546. [CrossRef] [PubMed]

6. dos Santos, M.C.; Pinheiro, V.H.C.; do Desterro, F.S.M.; de Avellar, R.K.; Schirru, R.; dos Santos Nicolau, A.; de Lima, A.M.M. Deep rectifier neural network applied to the accident identification problem in a PWR nuclear power plant. Ann. Nucl. Energy 2019, 133, 400-408. [CrossRef]

7. Malizia, A.; Carestia, M.; Cafarelli, C.; Milanese, L.; Pagannone, S.; Pappalardo, A.; Pedemonte, M.; Latini, G.; Barlascini, O.; Fiorini, E. The free license codes as Decision Support System (DSS) for the emergency planning to simulate radioactive releases in case of accidents in the new generation energy plants. WSEAS Trans. Environ. Dev. 2014, 10, 453-464.

8. Sweeck, L.; Camps, J.; Mikailova, R.; Almahayni, T. Role of modelling in monitoring soil and food during different stages of a nuclear emergency. J. Environ. Radioact. 2020, 225, 106444. [CrossRef] [PubMed]

9. Hsieh, M.-H.; Hwang, S.-L.; Liu, K.H.; Liang, S.-F.M.; Chuang, C.-F. A Decision Support System for Identifying Abnormal Operating Procedures in a Nuclear Power Plant. Nucl. Eng. Des. 2012, 249, 413-418. [CrossRef]

10. dos Santos Nicolau, A.; Schirru, R. A new methodology for diagnosis system with 'Don't Know'response for Nuclear Power Plant. Ann. Nucl. Energy 2017, 100, 91-97. [CrossRef]

11. Fernandez, M.G.; Tokuhiro, A.; Welter, K.; Wu, Q. Nuclear energy system's behavior and decision making using machine learning. Nucl. Eng. Des. 2017, 324, 27-34. [CrossRef]

12. Iwasaki, T.; Sekiyama, T.T.; Nakajima, T.; Watanabe, A.; Suzuki, Y.; Kondo, H.; Morino, Y.; Terada, H.; Nagai, H.; Takigawa, M. Intercomparison of numerical atmospheric dispersion prediction models for emergency response to emissions of radionuclides with limited source information in the Fukushima Dai-ichi nuclear power plant accident. Atmos. Environ. 2019, $214,116830$. [CrossRef]

13. IAEA. Lessons Learned from the Response to Radiation Emergencies (1945-2010); International Atomic Energy Agency: Vienna, Austria, 2012.

14. Gluzman, S. The Chernobyl accident-A personal perspective. Clin. Oncol. 2011, 23, 306-307. [CrossRef] [PubMed]

15. Nohrstedt, S.A. The information crisis in Sweden after Chernobyl. Media Cult. Soc. 1991, 13, 477-497. [CrossRef]

16. Cheng, Y.-H.; Shih, C.; Chiang, S.-C.; Weng, T.-L. Introducing PCTRAN as an evaluation tool for nuclear power plant emergency responses. Ann. Nucl. Energy 2012, 40, 122-129. [CrossRef]

17. Poa, L.-C.C.; Kimb, J. PCTRAN Analysis of Fukushima Event. In Proceedings of the Transactions of the Korean Nuclear Society Spring Meeting, Taebaek, Korea, 26-27 May 2011.

18. Khan, A.H.; Islam, M.S. A PCTRAN-Based Investigation On The Effect Of Inadvertent Control Rod Withdrawal On The ThermalHydraulic Parameters Of A Vver-1200 Nuclear Power Reactor. Acta Mech. Malays. 2019, 2, 32-38. [CrossRef]

19. Po, L.-C.C. Conceptual Design of an Accident Prevention System for Light Water Reactors Using Artificial Neural Network and High-Speed Simulator. Nucl. Technol. 2020, 206, 505-513. [CrossRef]

20. Korea Electric Power Corporation, Korea Hydro \& Nuclear Power Co., Ltd. Apr1400-Design Control Document Tier 2. In Chapter 15-Transient and Accident Analyses; US.NRC: Rockville, MD, USA, 2018; pp. 1-755.

21. Korea Electric Power Corporation, Korea Hydro \& Nuclear Power Co., Ltd. Apr1400-Design Control Document Tier 2. In Chapter 6-Engineered Safety Features; US.NRC: Rockville, MD, USA, 2018; pp. 1-801. 
22. Korea Electric Power Corporation, Korea Hydro \& Nuclear Power Co., Ltd. Apr1400-Design Control Document Tier 2. In Chapter 19-Probabilistic Risk Assessment and Severe Accident Evaluation; US.NRC: Rockville, MD, USA, 2018; pp. 1-2245.

23. IAEA. PCTRAN Generic Pressurized Water Reactor Simulator Exercise Handbook; International Atomic Energy Agency: Vienna, Austria, 2019.

24. MST. PCTRAN/APR1400 Design Basis and Severe Accident Simulator for APR1400; Micro-Simulation Technology: Seoul, Korea, 2015; pp. 1-241. 